\title{
Diastereo- and enantioselective preparation of cyclopropanol derivatives
}

\author{
Marwan Simaan and Ilan Marek
}

\section{Full Research Paper}

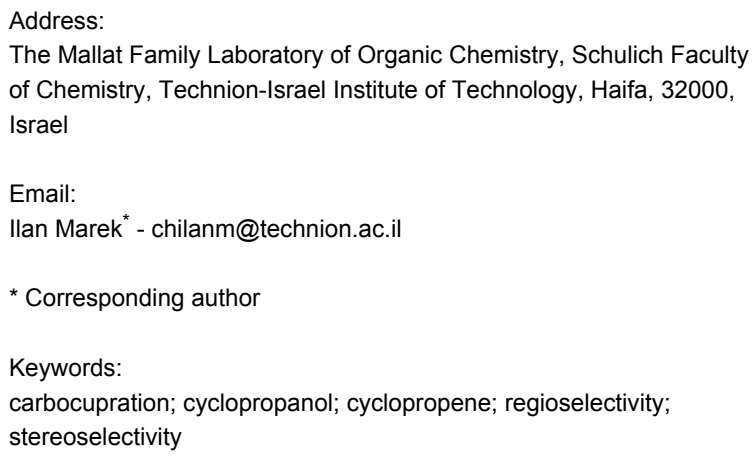

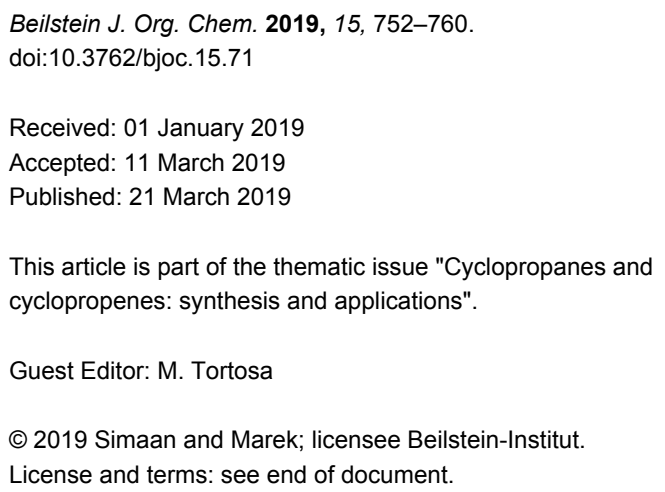

\begin{abstract}
The diastereoselective carbocupration reaction of alkoxy-functionalized cyclopropene derivatives, followed by a subsequent trapping of the resulting cyclopropylmetal species with an electrophilic source of oxygen (oxenoid) afforded various tetrasubstituted cyclopropanol derivatives in high diastereo- and enantiomeric ratios. Similarly, the enantioselective copper-catalyzed carbomagnesiation/oxidation (or amination) sequence on achiral nonfunctionalized cyclopropenes provided the desired cyclopropanol (and cyclopropylamine) derivatives in excellent diastereo- and enantiomeric excesses.
\end{abstract}

\section{Introduction}

The highly strained structure and bonding properties of cyclopropyl rings have constantly fascinated successive generations of chemists. These small carbocycles are known to have high ring strain $(27.5 \mathrm{kcal} / \mathrm{mol})$ and limited degrees of freedom, making them very attractive substrates for various chemical transformations [1]. The cyclopropane subunit is also present in many biologically important compounds such as pheromones, fatty acid metabolites, unusual amino acids and possess interesting herbicidal, insecticidal, antibiotic, antibacterial, antifungal, antiviral and antitumor activities [2]. For these reasons, cyclopropanes have been extensively studied and numerous ap- proaches have been described for their preparation [3]. Among all possible three-membered ring subunits that have been reported, cyclopropanols have recently attracted renewed attention as they are not only contained in many natural products but they are also important precursors in the synthesis of various biologically active molecules and pharmaceuticals such as antidepressants, antiviral and antibacterial drugs [4]. Cyclopropanols and their derivatives are considered to be carbocyclic homologues of enols presenting similar chemical properties which are caused by the unsaturated character of the cyclopropyl ring. Although cyclopropanols are usually less reactive 
than enols and enolates, their chemical properties are somehow more diverse as they undergo useful transformations either with preservation or rupture of the cyclic structure [5]. Several reliable approaches to produce cyclopropanols have been reported in the literature (Scheme 1) [6] but a number of challenges still exist particularly for the stereoselective preparation of cyclopropanols of high structural complexity and substitution pattern. Since the first synthesis of cyclopropanol by Cottle [7], the most popular methods for the preparation of cyclopropanols rely on the transformation of enolates [8,9], silyl enol ether [1012], vinyl borane [13-17], Fischer carbene addition [18], addi- tion of nucleophiles to carbonyl groups [19-25], elimination [26,27], oxidation [28] or on the Kulinkovich reaction [29-41] as summarized in Scheme 1. However, and despite the increasing and justified popularity of all of these methods, the short summary described in Scheme 1 emphasizes an intrinsic problem: a different strategy is required for every cyclopropanol and cyclopropylamine that one needs to prepare, limiting the rapid structural diversification which is usually essential for biological studies. From this rapid tour d'horizon, it is clear that if one could design a stereoselective synthetic pathway to afford polysubstituted cyclopropanols (or cyclopropylamines) potentially
Imamoto et al. [8]<smiles>CC1CC1(O)c1ccccc1</smiles>

Oshima et al. [9]<smiles>CC(=O)C(F)I</smiles>

1) $\mathrm{Et}_{2} \mathrm{Zn}$

2) $\mathrm{CH}_{2} \mathrm{I}_{2}$

R<smiles>[R]C1CC1(C)O</smiles>

dr up to $93: 7$

Barluenga et al. [18]<smiles>[R]C=C([R])[CH]OC([R])(C)C(=O)OC</smiles><smiles>[R]C1([R])C([R])(O)C1([R])O</smiles>

dr up to $98: 2$
Matsubara et al. [19,20]

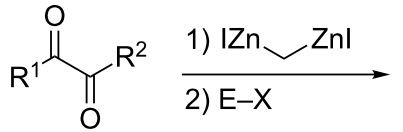<smiles>[R]C1(OF)CC1([R])OF</smiles>

only cis

Walsh et al. [15,21]

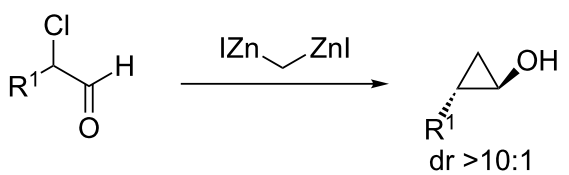

Kulinkovich et al. [29-41]

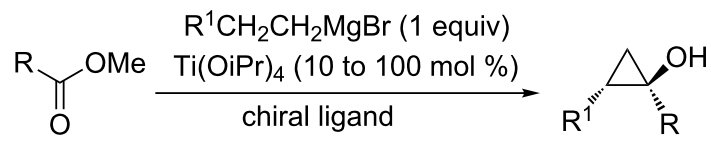

Trost et al. [26,27]

er up to $93: 7$

Shi et al. [12]

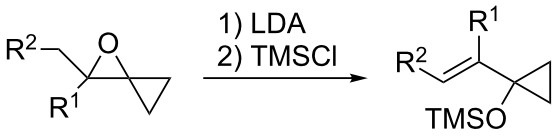

Wright et al. [28]

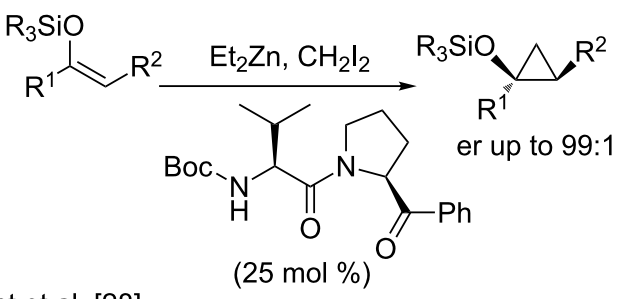

\section{Salaün et al. [23-25]}
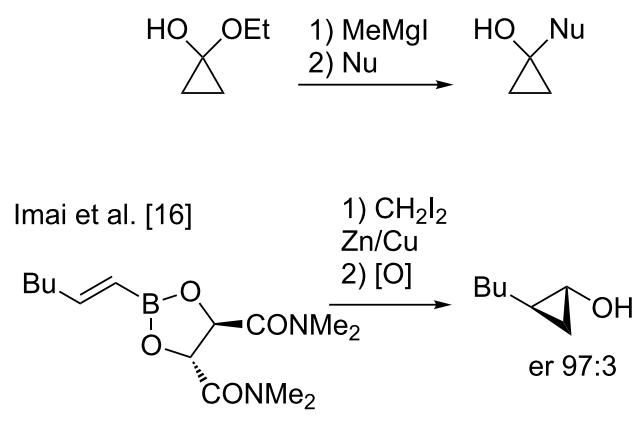

Charette et al. [17]

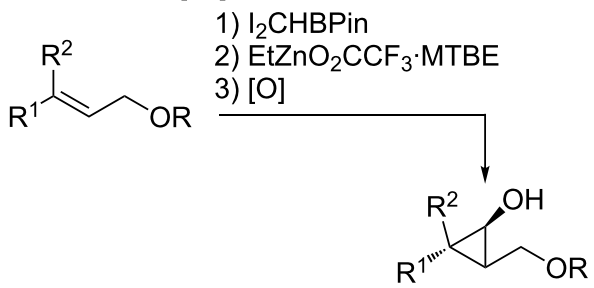


bearing several diastereo- and enantiomerically enriched adjacent stereogenic centers, including quaternary carbon stereocenters, as single diastereo- and enantiomer from a simple precursor, it would certainly provide an additional and useful entry to the synthesis of these heterosubstituted three-membered rings.

\section{Results and Discussion}

To reach these goals, we are describing herein the diastereoand enantioselective carbometalation reaction of cyclopropenes to provide cyclopropylmetal species. By subsequent stereoselective reactions of the cyclopropylmetal species with an electrophilic source of oxygen (or nitrogen), cyclopropanols (and cyclopropylamines) should be easily accessible (Scheme 2).

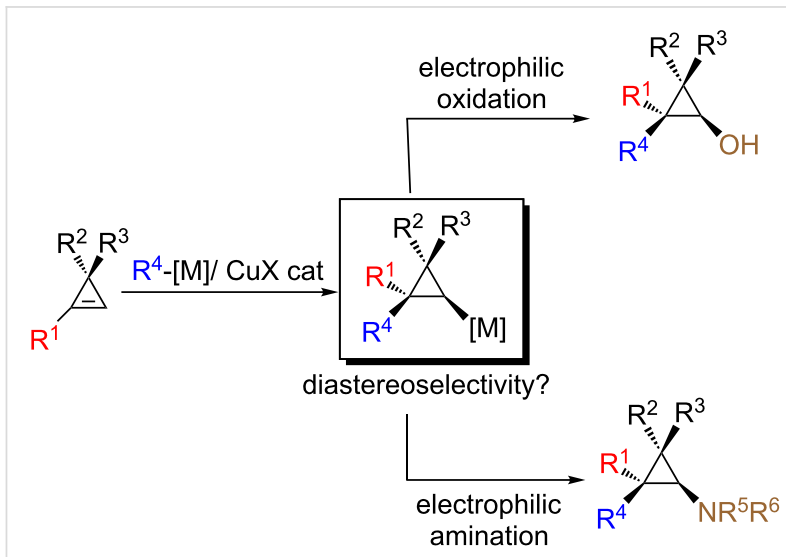

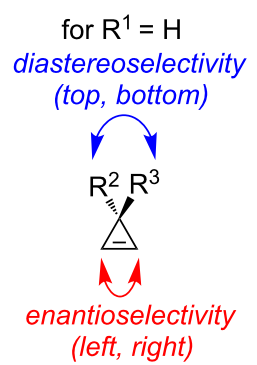

Scheme 2: General approach to the preparation of cyclopropanol and cyclopropylamine derivatives.

In order to assemble both cyclopropanols and cyclopropylamines from a single and unique precursor in a single-pot reaction double facial selection by the catalyst is required: (i) regio- selectivity when $\mathrm{R}^{1}$ is different to $\mathrm{H}$ and enantioselectivity when $\mathrm{R}^{1}$ is equal to $\mathrm{H}$ (left or right) and (ii) diastereotopic face selection (top or bottom) as described in Scheme 2. Since the pioneering addition of a carbon-metal bond (carbometalation) across the double bond of cyclopropenes [42], a very large number of groups have reported the addition of organometallic species demonstrating the generality of this approach for the preparation of cyclopropanes [43-63]. To achieve good diastereoselectivity during the carbometalation reaction, few conditions needed to be fulfilled in the design of the starting cyclopropenyl ring (Figure 1):

1. The presence of a coordinating group (such as an oxygen) at the $\mathrm{C}_{3}$ position is crucial for the selective facial addition of the incoming organometallic species.

2. The presence of a bulky substituent (alkyl or aryl) at the opposite face at the $\mathrm{C}_{3}$ position might equally be important as it might induce an additional steric parameter leading to a potentially more selective carbometalation reaction.

3. The substitution pattern on the double bond needs to be addressed carefully as it plays an important role in the control of the regioselectivity of the reaction pathway. An alkyl group on the $\mathrm{C}_{1}$ position of the cyclopropene should control the regioselectivity of the addition of the organometallic species to give the more stable secondary cyclopropylmetal species (metal at $\mathrm{C}_{2}$ ).

We therefore decided to start our research with cyclopropanes bearing an electron-rich methoxy group on one side of the ring and a phenyl or methyl substituent on the opposite side, respectively. Following reported methods from the literature [64-67], cyclopropenes 3 were easily prepared through the well-known $\mathrm{Rh}^{\mathrm{II}}$-catalyzed decomposition of diazo esters in the presence of alkynes to give cyclopropenyl esters $\mathbf{1}$. Reduction of $\mathbf{1}$ using DIBAL-H afforded cyclopropenyl alcohols 2 and subsequent protection of the primary alcohols gave $\mathbf{3}$ in good yields (Scheme 3).

First, we checked that the carbometalation reaction was regioand diastereoselective by addition of lower order cyanocuprate, easily obtained from the corresponding organolithium and a stoichiometric amount of $\mathrm{CuCN}$ (Scheme 4) [68-70].

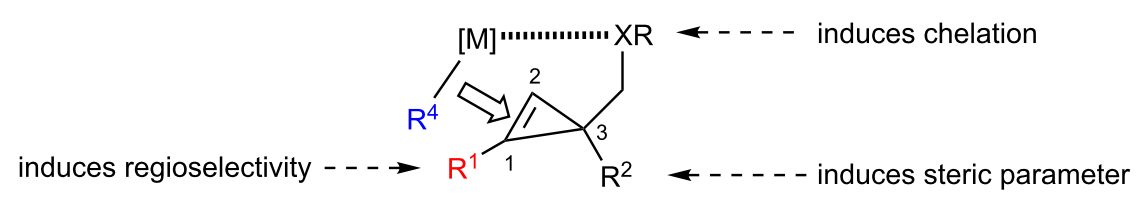




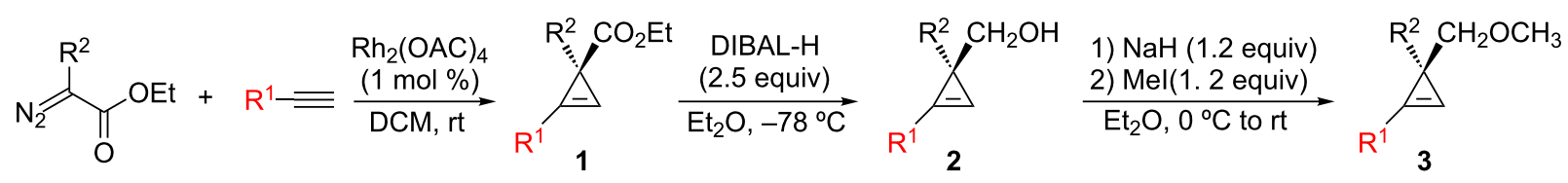

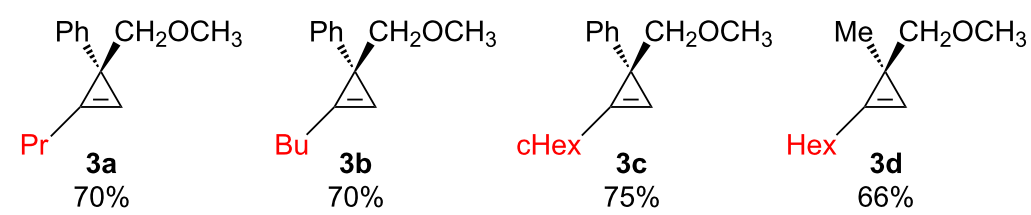

Scheme 3: Preparation of cyclopropenyl methyl ethers 3a-d.
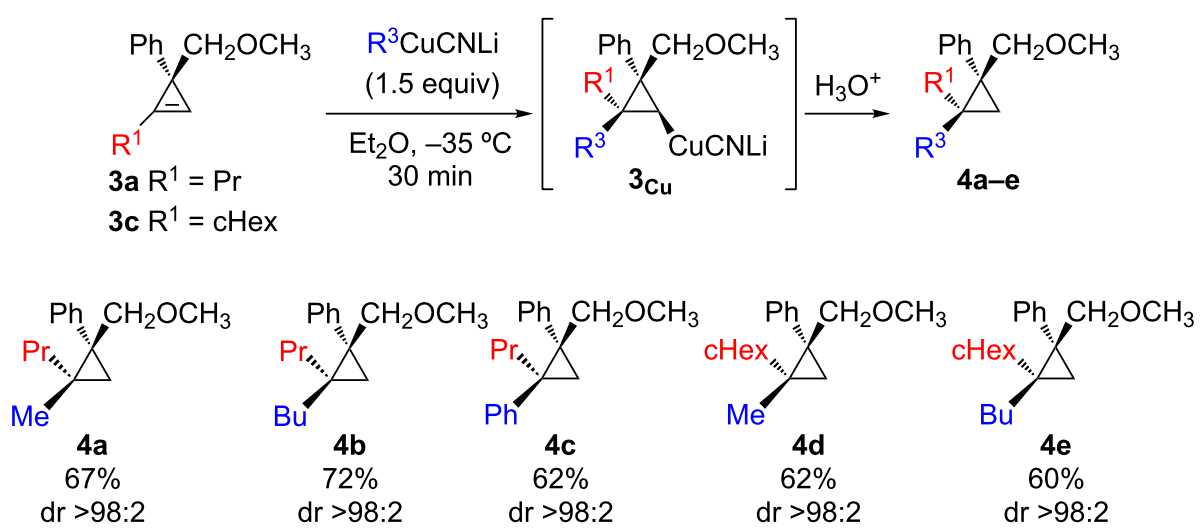

Scheme 4: Regio- and diastereoselective carbocupration of cyclopropenyl methyl ethers 3a,c.

The addition reaction proceeds similarly for the addition of alkyl- or arylcuprate $(\mathbf{4 a}, \mathbf{b}$ and $\mathbf{4 c})$ as well as for the addition on cyclopropene possessing either a primary or secondary alkyl group at the vinylic carbon center $(\mathbf{4 a}-\mathbf{c}$ and $\mathbf{4 d}, \mathbf{e})$. Having in hand diastereoisomerically pure and configurationally stable cyclopropylcopper species $\mathbf{3}_{\mathbf{C u}}$, we next turned our attention to their stereoselective oxidation reaction (Scheme 5). Considering electrophilic oxidation processes of organometallic species, molecular oxygen seems to be the most obvious choice due to its abundancy and low cost. Nevertheless, the reaction of molecular oxygen with a organocopper species usually proceeds through single-electron transfer to dioxygen, leading to either a loss of stereoselectivity, degradation of the organocopper or to the formation of dimer as major products [71]. Therefore, it was clear that a different approach for the oxidation process was needed. Oxenoid, possessing the general structure M-O-LG, with a metal and a leaving group connected to an oxygen atom, have been shown to be an excellent electrophilic oxygen source for nucleophilic organometallic species [72]. Since the original discovery of Müller and Töpel of lithiated peroxides [73], several studies have been reported on the reactivity of oxenoids [74-77], indicating that the reaction of a nucleophile with oxenoid proceeds through an $\mathrm{S}_{\mathrm{N}} 2$ process [74]. Following the carbocupration of cyclopropene 3 into cyclopropylcopper species, the subsequent oxidation with the amphiphilic lithiated hydroperoxide $t$-BuOOLi (oxenoid), simply generated by deprotonation of $t$ - $\mathrm{BuOOH}$ with $n$-BuLi, led to the copper alkoxide, as anticipated, without the formation of free radical intermediates. As already reported [78], the expected 2,2,3,3-tetrasubstituted cyclopropanols 5 were obtained as single diastereoisomers (Scheme 5).

The reaction proceeded for all $\mathrm{R}^{1}$ and $\mathrm{R}^{2}$ groups tested and determination of the stereochemistry confirmed that the oxidation reaction proceeds with pure retention of configuration at the metalated center (intramolecular $\mathrm{S}_{\mathrm{N}} 2$ reaction or 1,2-metalate rearrangement) [78-80]. It should be noted that when the same sequence of diastereoselective carbometalation/oxidation was performed on cyclopropenyl ester $\mathbf{1}$, the in situ-formed donor-acceptor cyclopropanol undergoes a selective ring- 
as reported in [78]

1,2-metallate rearrangement
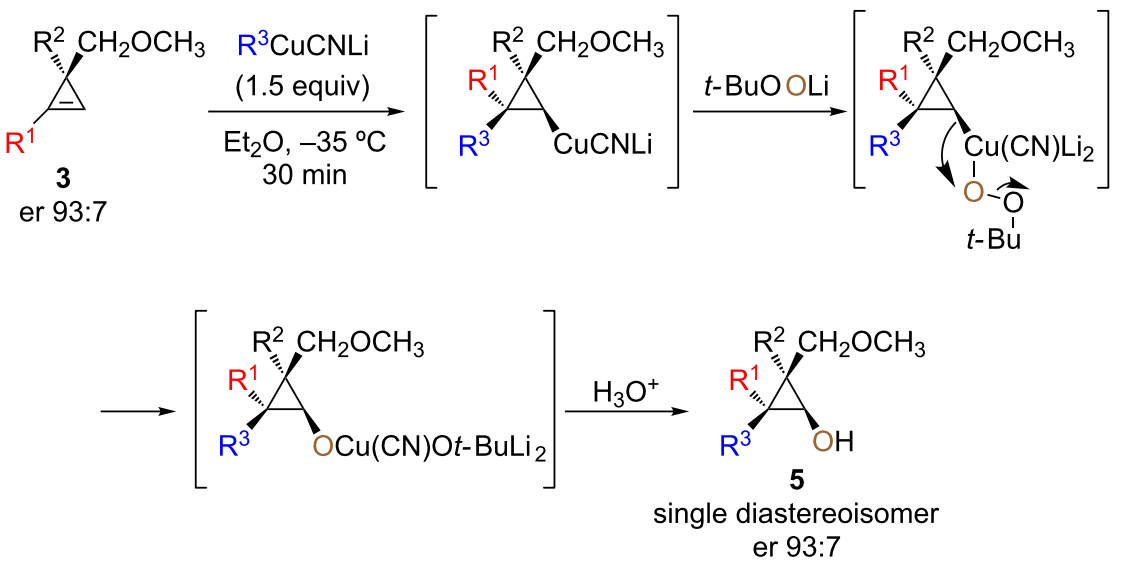

Scheme 5: Diastereoselective formation of cyclopropanols.

opening to provide the acyclic product possessing a quaternary carbon stereocenter [57]. As the enantioselective synthesis of the cyclopropenylmethyl ether $\mathbf{3}$ was easily achieved in high enantiomeric ratio (er 93:7, Scheme $5[78,81,82]$ ), the subsequent combined diastereoselective carbometalation reaction and oxidation gave the enantiomerically enriched cyclopropanols $\mathbf{5}$ as unique diastereoisomer with the same enantiomeric ratio as the starting material (Scheme 5, dr 98:2:0:0, er 93:7). Having established the optimized reaction conditions for the preparation of diastereomerically pure 2,2,3,3-tetrasubstituted cyclopropanol derivatives $\mathbf{5}$, we were interested to expand the scope of this transformation and include different types of cyclopropene precursors. We concentrated our efforts on the reaction of diversely substituted 3-methyl-3-arylcyclopropenes $\mathbf{6}$. In this case, as there is no coordinating functionality to dictate the facial selectivity, the control of the diastereoselectivity may be more challenging. Performing the same carbocupration/oxidation sequence on 3-methyl-3-phenylcyclopropene $\mathbf{6 a}, \mathbf{b}$ $\left(\mathrm{R}^{1}=\mathrm{H}\right)$, we were pleased to observe that trisubstituted cyclopropanols $7 \mathbf{a}-\mathbf{h}$ were obtained in good yields with excellent diastereoselectivities (Scheme 6).

The addition of primary, secondary and tertiary alkylcuprates or arylcuprates proceeded smoothly to give the desired cyclopropanols (7a-h) after hydrolysis. In all cases, the easily prepared cyclopropanol derivatives were obtained with the methyl, the incoming organometallic and the alcohol in the syn-orientation which was determined through comparison of the hydrolyzed carbometalated products with compounds already described in the literature [83]. To further increase the structural complexity of the final cyclopropanols, we also tested the reaction on nonfunctionalized trisubstituted cyclopropenes $(\mathbf{6 c - g})$. Addition of primary alkyl- or arylcuprates followed by the oxidation of the cyclopropylcopper species proceeded equally well and gave the corresponding cyclopropanols possessing two adjacent quaternary carbon stereocenters $(\mathbf{7} \mathbf{i}-\mathbf{r})$ in good yields and excellent diastereomeric ratios. Here again, the methyl, the alkyl group from the organometallic and the alcohol in the resulting cyclopropanols are syn-oriented as previously observed. As reported in a different context, the nature of the two substituents on the cyclopropene rings could be changed without drastically altering the selectivity of the reaction $[83,91]$.

We were also interested to develop the access to non-racemic unfunctionalized cyclopropanols. Based on the pioneering work of Lautens [62], Nakamura [60], Fox [61], Gevorgyan [51] and Tortosa [84], we anticipated that an enantioselective copper-catalyzed carbometalation reaction $[83,85]$ would be an ideal solution to access the desired polysubstituted enantioenriched cyclopropanols. As reported, the copper-catalyzed diastereo- and enantioselective carbomagnesiation reaction of cyclopropenes 6 was easily achieved in the presence of $(R, S)$-Josiphos (2.2 mol \%, Scheme 7). Having in hand, diastereoisomerically pure and enantiomerically enriched cyclopropylmagnesium species $\mathbf{6}_{\mathbf{M g B r}}$, the selective oxidation reaction of the copper species, resulting from a transmetalation reaction, was similarly achieved by reaction with oxenoid [71,79,80,86-89]. In all cases, cyclopropanols 7 were obtained as single diastereoisomer (dr 98:2:0:0) with excellent enantiomeric ratios (er up to 99:1, Scheme 7). Following the same concept of copper-catalyzed diastereo- and enantioselective carbomagnesiation reaction of cyclopropenes 6 followed now by a selective electrophilic amination reaction, a powerful entry to cyclopropylamines as single diastereoisomer and in excellent enantiomeric ratios could also be achieved (Scheme 7) [89]. However, the enantioselective and catalytic copper-catalyzed carbomagnesiation 


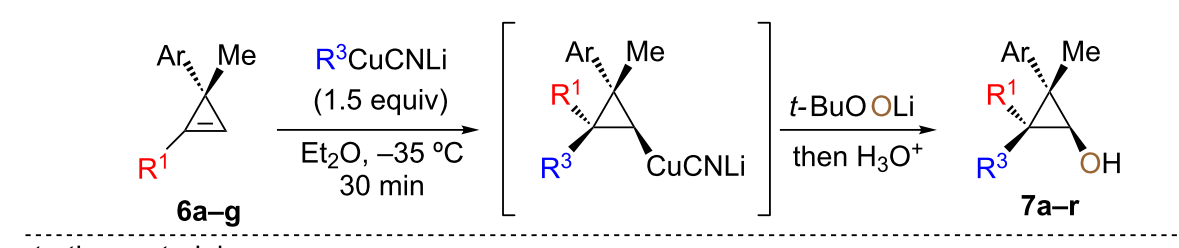

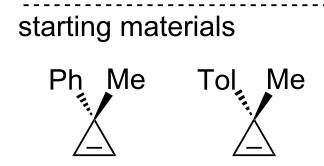

$6 a$

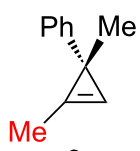

$6 c$

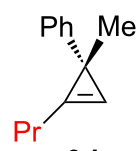

6d

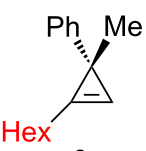

$6 \mathrm{e}$

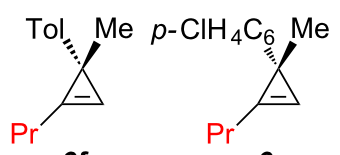

$6 \mathrm{~g}$

scope

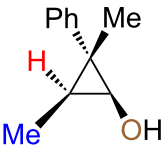

$7 a$

$65 \%$

dr 98:2:0:0

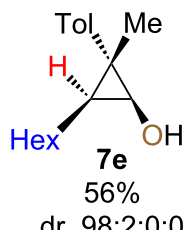

dr 98:2:0:0

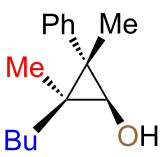

$7 i$

$65 \%$

dr 98:2:0:0

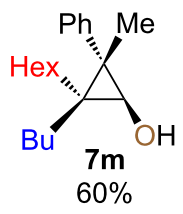

dr 98:2:0:0

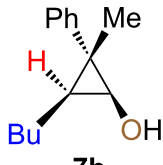

$7 \mathbf{b}$

$62 \%$

dr 98:2:0:0
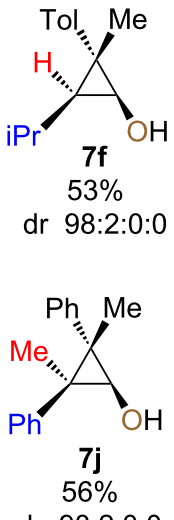

dr $98: 2: 0: 0$

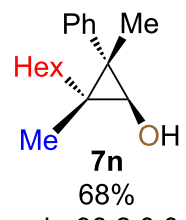

dr $98: 2: 0: 0$
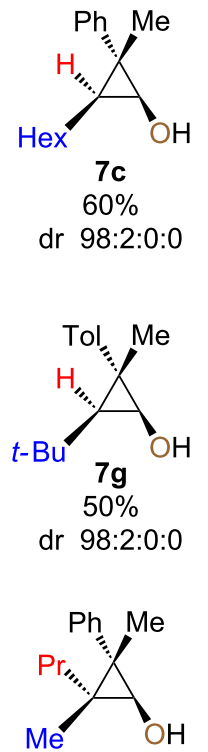

$7 \mathbf{k}$

$70 \%$

dr 98:2:0:0

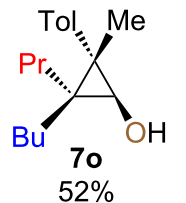

dr 98:2:0:0
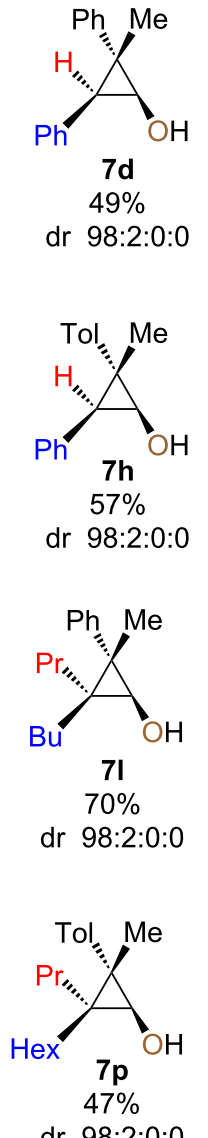
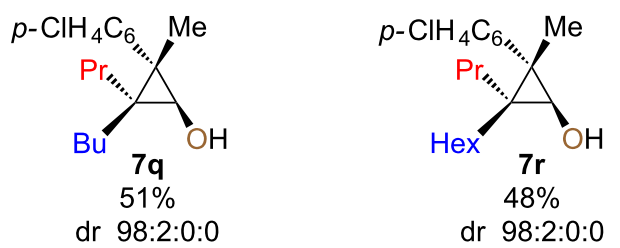

Scheme 6: Diastereoselective carbometalation/oxidation of nonfunctionalized cyclopropenes 6 .

reaction gave poor enantiomeric ratios for the addition of vinyl, aryl and allyl groups and alternative strategies have been recently developed in our research group [90-92].

\section{Conclusion}

In conclusion, we have successfully merged the regio- and diastereoselective carbocupration reaction of alkoxy-functionali- 
as described in [89]
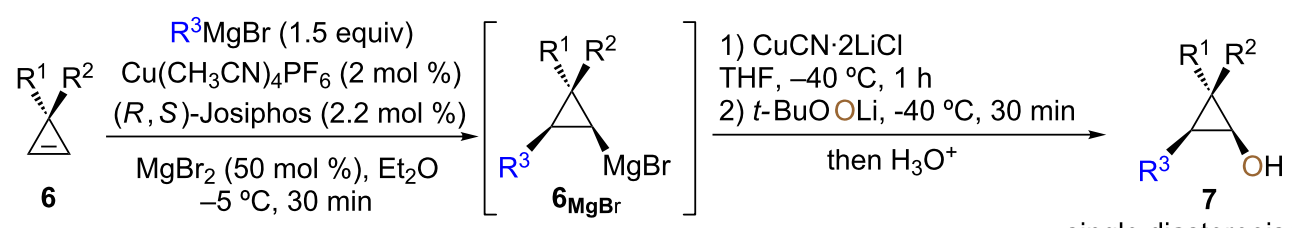

single diastereoisomer

er up to $99: 1$

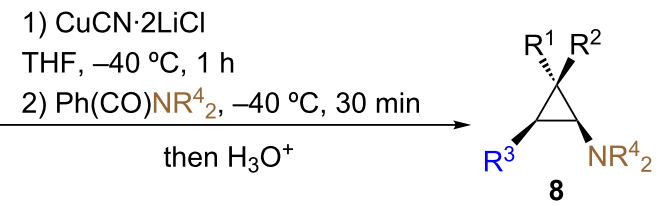

single diastereoisomer er up to $99: 1$

Scheme 7: Preparation of diastereoisomerically pure and enantioenriched cyclopropanols and cyclopropylamines.

zed cyclopropenes with electrophilic oxidation of the resulting cyclopropylcopper species to afford 2,2,3,3-polysubstituted cyclopropanol derivatives bearing two adjacent quaternary stereogenic centers in a single pot operation. The simple preparation of enantiomerically enriched cyclopropene afforded the corresponding cyclopropanols in high enantiomeric excess. This transformation was then applied to unfunctionalized diversely substituted cyclopropenes. Using the catalytic and enantioselective carbometalation reaction of unfunctionalized cyclopropenes followed by an electrophilic oxidation reaction, polysubstituted cyclopropanols were obtained as single diastereoisomer with high enantiomeric ratios. In all cases, the configurationally stable cyclopropylmetal species reacted with retention of configuration with those electrophiles opening a new approach to $O$-heterosubstituted cyclopropyl rings.

\section{Experimental}

\section{General procedure for the carbocupration reaction of $\mathbf{3 a}, \mathbf{c}$ with $\mathrm{RCuCNLi}$}

To a suspension of $\mathrm{CuCN}$ (1.5 equiv) in $8 \mathrm{~mL}$ of $\mathrm{Et}_{2} \mathrm{O}$ was added alkyllithium dropwise at $-35^{\circ} \mathrm{C}$ ( 2 equiv). The resulting mixture (pale yellow in case of MeLi and $\mathrm{PhLi}$ and dark brown in case of $n$-BuLi and $n$-HexLi) was allowed to stir for $30 \mathrm{~min}$. Cyclopropene 3a,c ( 1 equiv in $2 \mathrm{~mL} / \mathrm{mmol}$ of $\mathrm{Et}_{2} \mathrm{O}$ ) was added at that temperature and the reaction mixture was stirred until TLC shows complete consumption of the starting material (eluent hexane/EtOAc 9:1, ca. $30 \mathrm{~min}$ ). The reaction was then quenched with an aqueous solution of $\mathrm{NH}_{4} \mathrm{Cl} / \mathrm{NH}_{4} \mathrm{OH}$ (2:1). The aqueous layer was extracted twice with EtOAc and the combined organic phases were washed with brine, dried over $\mathrm{MgSO}_{4}$, filtered, and concentrated under reduced pressure. The crude mixtures were then purified by flash chromatography using pentane/diethyl ether as eluent.

\section{General procedure for the combined carbocupration/oxidation sequence}

The reaction was performed on a $1 \mathrm{mmol}$ scale. To a suspension of $\mathrm{CuCN}$ (2 equiv) in $8 \mathrm{~mL}$ of $\mathrm{Et}_{2} \mathrm{O}$ was added alkyllithium dropwise at $-35{ }^{\circ} \mathrm{C}(2$ equiv/ $2 \mathrm{mmol})$. The resulting mixture (pale yellow in case of MeLi and PhLi and dark brown in case of $n$-BuLi and $n$-HexLi) was allowed to stir for $30 \mathrm{~min}$. Cyclopropene 6a-g ( 1 equiv/1 $\mathrm{mmol}$ in $2 \mathrm{~mL}$ of $\mathrm{Et}_{2} \mathrm{O}$ ) was added at that temperature and the reaction mixture was stirred until TLC shows complete consumption of the starting material (eluent hexane/EtOAc 9:1, ca. $30 \mathrm{~min}$ ). The oxenoid was prepared in a different flask by slowly adding $n$-BuLi (1.2 equiv) to a solution of tert-butyl hydroperoxide ( 2 equiv) in THF $(5 \mathrm{~mL} / 2 \mathrm{mmol})$ at $-80{ }^{\circ} \mathrm{C}$. After $30 \mathrm{~min}$ at $-80{ }^{\circ} \mathrm{C}$, the resulting $t$-BuOOLi was transferred to the organocopper dropwise at $-78^{\circ} \mathrm{C}$ via a cannula. The mixture (orange to brown) was stirred at this temperature until disappearance of the cyclopropylcopper species (followed by TLC, eluent hexane/EtOAc 9:1, ca. $30 \mathrm{~min}$ ). The reaction was then quenched with an aqueous solution of $\mathrm{NH}_{4} \mathrm{Cl} / \mathrm{NH}_{4} \mathrm{OH}$ (2:1). The aqueous layer was extracted twice with $\mathrm{Et}_{2} \mathrm{O}$ and the combined organic phases were washed with brine, dried over $\mathrm{MgSO}_{4}$, filtered, and concentrated under reduced pressure. Crude mixtures were then purified by flash chromatography using pentane/diethyl ether as eluent.

\section{Supporting Information}

\section{Supporting Information File 1}

Experimental part.

[https://www.beilstein-journals.org/bjoc/content/ supplementary/1860-5397-15-71-S1.pdf] 


\section{Acknowledgements}

This project has received funding from the European Union's Horizon 2020 research and innovation program under grant agreement No 786976. I. M. is holder of the Sir Michael and Lady Sobell Academic Chair.

\section{ORCID ${ }^{\circledR}$ iDs}

Ilan Marek - https://orcid.org/0000-0001-9154-2320

\section{References}

1. D'yakonov, V. A.; Trapeznikova, O. A.; de Meijere, A.; Dzhemilev, U. M. Chem. Rev. 2014, 114, 5775-5814. doi:10.1021/cr400291c

2. Salaün, J.; Bairds, M. S. Curr. Med. Chem. 1995, 2, 511-542.

3. Wong, H. N. C.; Hon, M.-Y.; Tse, C.-W.; Yip, Y.-C.; Tanko, J.; Hudlicky, T. Chem. Rev. 1989, 89, 165-198. doi:10.1021/cr00091a005

4. Haym, I.; Brimble, M. A. Org. Biomol. Chem. 2012, 10, 7649-7665. doi:10.1039/c2ob26082d

5. Orellana, A.; Nikolaev, A. Synthesis 2016, 48, 1741-1768. doi:10.1055/s-0035-1560442

6. Kulinkovich, O. G. Chem. Rev. 2003, 103, 2597-2632. doi:10.1021/cr010012i

7. Magrane, J. K., Jr.; Cottle, D. L. J. Am. Chem. Soc. 1942, 64, 484-487. doi:10.1021/ja01255a004

8. Imamoto, T.; Kamiya, Y.; Hatajima, T.; Takahashi, H. Tetrahedron Lett. 1989, 30, 5149-5152. doi:10.1016/s0040-4039(01)93471-9

9. Ito, S.; Shinokubo, H.; Oshima, K. Tetrahedron Lett. 1998, 39 , 5253-5256. doi:10.1016/s0040-4039(98)01036-3

10. Rubottom, G. M.; Lopez, M. I. J. Org. Chem. 1973, 38, 2097-2099. doi:10.1021/jo00951a032

11. Murai, S.; Aya, T.; Sonoda, N. J. Org. Chem. 1973, 38, 4354-4356. doi:10.1021/jo00964a037

12. Du, H.; Long, J.; Shi, Y. Org. Lett. 2006, 8, 2827-2829. doi:10.1021/ol0609659

13. Fontani, P.; Carboni, B.; Vaultier, M.; Maas, G. Synthesis 1991, 605-609. doi:10.1055/s-1991-26524

14. Pietruszka, J.; Widenmeyer, M. Synlett 1997, 977-979. doi:10.1055/s-1997-5790

15. Hussain, M. M.; Li, H.; Hussain, N.; Ureña, M.; Carroll, P. J.; Walsh, P. J. J. Am. Chem. Soc. 2009, 131, 6516-6524. doi:10.1021/ja900147s

16. Imai, T.; Mineta, H.; Nishida, S. J. Org. Chem. 1990, 55, 4986-4988. doi:10.1021/jo00304a004

17. Benoit, G.; Charette, A. B. J. Am. Chem. Soc. 2017, 139, 1364-1367. doi:10.1021/jacs.6b09090

18. Barluenga, J.; Suero, M. G.; Pérez-Sánchez, I.; Flórez, J. J. Am. Chem. Soc. 2008, 130, 2708-2709. doi:10.1021/ja074363b

19. Ukai, K.; Oshima, K.; Matsubara, S. J. Am. Chem. Soc. 2000, 122, 12047-12048. doi:10.1021/ja003360v

20. Matsubara, S.; Ukai, K.; Fushimi, H.; Yokota, Y.; Yoshino, H.; Oshima, K.; Omoto, K.; Ogawa, A.; Hioki, Y.; Fujimoto, H. Tetrahedron 2002, 58, 8255-8262. doi:10.1016/s0040-4020(02)00975-4

21. Cheng, K.; Carroll, P. J.; Walsh, P. J. Org. Lett. 2011, 13, 2346-2349. doi:10.1021/ol200597h

22. Turro, N. J. Acc. Chem. Res. 1969, 2, 25-32. doi:10.1021/ar50013a004

23. Salaun, J. Chem. Rev. 1983, 83, 619-632. doi:10.1021/cr00058a002
24. Salaün, J.; Bennani, F.; Compain, J. C.; Fadel, A.; Ollivier, J. J. Org. Chem. 1980, 45, 4129-4135. doi:10.1021/jo01309a012

25. Stolle, A.; Ollivier, J.; Piras, P. P.; Salaün, J.; de Meijere, A. J. Am. Chem. Soc. 1992, 114, 4051-4067. doi:10.1021/ja00037a006

26. Trost, B. M.; Bogdanowicz, M. J. J. Am. Chem. Soc. 1973, 95 , 289-290. doi:10.1021/ja00782a077

27. Trost, B. M.; Bogdanowicz, M. J. J. Am. Chem. Soc. 1973, 95, 5311-5321. doi:10.1021/ja00797a036

28. Longone, D. T.; Wright, W. D. Tetrahedron Lett. 1969, 10, 2859-2862. doi:10.1016/s0040-4039(01)88292-7

29. Kulinkovich, O. G.; Sviridov, S. V.; Vasilevskii, D. A.; Pritytskaya, T. S. Zh. Org. Khim. 1989, 25, 2244.

J. Org. Chem. USSR 1989, 25, 2027.

30. Kulinkovich, O. G.; Sviridov, S. V.; Vasilevski, D. A. Synthesis 1991, 234. doi:10.1055/s-1991-26431

31. Sviridov, S. V.; Vasilevskii, D. A.; Savchenko, A. I.; Pritytskaya, T. S.; Kulinkovich, O. G. Zh. Org. Khim. 1991, 27, 294. J. Org. Chem. USSR 1991, 27, 250.

32. Vasilevskii, D. A.; Savchenko, A. I.; Sviridov, S. V.; Kulinkovich, O. G. Zh. Org. Khim. 1991, 27, 1428.

J. Org. Chem. USSR 1991, 27, 1249.

33. Savchenko, I. A.; Kulinkovich, O. G. Zh. Org. Khim. 1997, 33, 913. Russ. J. Org. Chem. 1997, 33, 846.

34. Savchenko, A. I.; Shevchuk, T. A.; Kulinkovich, O. G. Zh. Org. Khim. 1999, 35, 244. Russ. J. Org. Chem. 1999, 35, 225.

35. Lee, J.; Kim, H.; Cha, J. J. Am. Chem. Soc. 1996, 118, 4198-4199. doi:10.1021/ja954147f

36. Epstein, O. L.; Savchenko, A. I.; Kulinkovich, O. G. Tetrahedron Lett. 1999, 40, 5935-5938. doi:10.1016/s0040-4039(99)01177-6

37. Kananovich, D. G.; Kulinkovich, O. G. Tetrahedron 2008, 64 1536-1547. doi:10.1016/j.tet.2007.10.075

38. Lee, J.; Kang, C. H.; Kim, H.; Cha, J. K. J. Am. Chem. Soc. 1996, 118, 291-292. doi:10.1021/ja953055n

39. Kasatkin, A.; Sato, F. Tetrahedron Lett. 1995, 36, 6079-6082. doi:10.1016/0040-4039(95)01208-y

40. Corey, E. J.; Rao, S. A.; Noe, M. C. J. Am. Chem. Soc. 1994, 116, 9345-9346. doi:10.1021/ja00099a068

41. Kulinkovich, O. G.; Kananovich, D. G.; Lopp, M.; Snieckus, V. Adv. Synth. Catal. 2014, 356, 3615-3626. doi:10.1002/adsc. 201400480

42. Welch, J. G.; Magid, R. M. J. Am. Chem. Soc. 1967, 89, 5300-5301. doi:10.1021/ja00996a047

43. Lukina, M. Y.; Rudavshevskaya, T. Y.; Nesmeyanova, O. A. Dokl. Akad. Nauk. SSSR 1970, 190, 133.

44. Avezov, I. B.; Bolesov, I. G.; Levina, R. Y. J. Org. Chem. USSR 1975, 10, 2129.

45. Moiseenkov, A. M.; Czeskis, B. A.; Semenovsky, A. V. J. Chem. Soc., Chem. Commun. 1982, 109-110. doi:10.1039/c39820000109

46. Lehmkuhl, H.; Mehler, K. Justus Liebigs Ann. Chem. 1978, 1841-1853. doi:10.1002/jlac.197819781117

47. Lehmkuhl, H.; Mehler, K. Liebigs Ann. Chem. 1982, 2244-2246. doi:10.1002/jlac.198219821215

48. Richey, H. G.; Watkins, E. K. J. Chem. Soc., Chem. Commun. 1984, 772-773. doi:10.1039/c39840000772

49. Watkins, E. K.; Richey, H. G. Organometallics 1992, 11, 3785-3794. doi:10.1021/om00059a048

50. Stoll, A. T.; Negishi, E.-i. Tetrahedron Lett. 1985, 26, 5671-5674. doi:10.1016/s0040-4039(01)80915-1 
51. Rubin, M.; Rubina, M.; Gevorgyan, V. Chem. Rev. 2007, 107, 3117-3179. doi:10.1021/cr050988

52. Lautens, M.; Klute, W.; Tam, W. Chem. Rev. 1996, 96, 49-92. doi:10.1021/cr950016।

53. Marek, I.; Simaan, S.; Masarwa, A. Angew. Chem., Int. Ed. 2007, 46, 7364-7376. doi:10.1002/anie.200604774

54. Miege, F.; Meyer, C.; Cossy, J. Beilstein J. Org. Chem. 2011, 7, 717-734. doi:10.3762/bjoc.7.82

55. Rubin, M.; Rubina, M.; Gevorgyan, V. Synthesis 2006, 1221-1245. doi:10.1055/s-2006-926404

56. Isaka, M.; Nakamura, E. J. Am. Chem. Soc. 1990, 112, 7428-7430. doi:10.1021/ja00176a072

57. Delaye, P.-O.; Didier, D.; Marek, I. Angew. Chem., Int. Ed. 2013, 52, 5333-5337. doi:10.1002/anie.201300664

58. Roy, S. R.; Didier, D.; Kleiner, A.; Marek, I. Chem. Sci. 2016, 7, 5989-5994. doi:10.1039/c6sc02191c

59. Liao, L.-a.; Fox, J. M. J. Am. Chem. Soc. 2002, 124, 14322-14323. doi:10.1021/ja0278234

60. Nakamura, M.; Hirai, A.; Nakamura, E. J. Am. Chem. Soc. 2000, 122, 978-979. doi:10.1021/ja983066r

61. Liu, X.; Fox, J. M. J. Am. Chem. Soc. 2006, 128, 5600-5601. doi:10.1021/ja058101q

62. Krämer, K.; Leong, P.; Lautens, M. Org. Lett. 2011, 13, 819-821. doi:10.1021/ol1029904

63. Rubin, M.; Gevorgyan, V. Synthesis 2004, 796-800. doi:10.1055/s-2003-44368

64. Baird, M. S. In Carbocyclic Three-Membered Ring Compounds, 4th ed.; de Meijere, A., Ed.; Georg Thieme Verlag: Stuttgart; Germany, 1996; Vol. 17, pp 2695 ff.

65. Petiniot, N.; Anciaux, A. J.; Noels, A. F.; Hubert, A. J.; Teyssié, P. Tetrahedron Lett. 1978, 19, 1239-1242. doi:10.1016/s0040-4039(01)94511-3

66. Panne, P.; Fox, J. M. J. Am. Chem. Soc. 2007, 129, 22-23. doi:10.1021/ja0660195

67. Díaz-Requejo, M. M.; Mairena, M. A.; Belderrain, T. R.; Nicasio, M. C.; Trofimenko, S.; Pérez, P. J. Chem. Commun. 2001, 1804-1805. doi:10.1039/b105020f

68. Lipshutz, B. H.; Wilhelm, R. S. J. Am. Chem. Soc. 1982, 104, 4696-4698. doi:10.1021/ja00381a041

69. Lipshutz, B. H.; Kozlowski, J.; Wilhelm, R. S. J. Am. Chem. Soc. 1982, 104, 2305-2307. doi:10.1021/ja00372a032

70. Lipshutz, B. H.; Wilhelm, R. S.; Floyd, D. M. J. Am. Chem. Soc. 1981, 103, 7672-7674. doi:10.1021/ja00415a055

71. Minko, Y.; Marek, I. Org. Biomol. Chem. 2014, 12, 1535-1546. doi:10.1039/c3ob42349b

72. Boche, G.; Lohrenz, J. C. W. Chem. Rev. 2001, 101, 697-756. doi:10.1021/cr940260x

73. Müller, E.; Töpel, T. Ber. Dtsch. Chem. Ges. B 1939, 72, 273-290. doi:10.1002/cber.19390720208

74. Boche, G.; Möbus, K.; Harms, K.; Lohrenz, J. C. W.; Marsch, M. Chem. - Eur. J. 1996, 2, 604-607. doi:10.1002/chem.19960020521

75. Möller, M.; Husemann, M.; Boche, G. J. Organomet. Chem. 2001, 624, 47-52. doi:10.1016/s0022-328x(00)00596-9

76. Warner, P.; Lu, S.-L. J. Org. Chem. 1976, 41, 1459-1461. doi:10.1021/jo00870a037

77. Surry, D. S.; Spring, D. R. Chem. Soc. Rev. 2006, 35, 218-225. doi:10.1039/b508391p

78. Simaan, M.; Delaye, P.-O.; Shi, M.; Marek, I. Angew. Chem., Int. Ed. 2015, 54, 12345-12348. doi:10.1002/anie.201412440
79. Minko, Y.; Pasco, M.; Lercher, L.; Botoshansky, M.; Marek, I. Nature 2012, 490, 522-526. doi:10.1038/nature11569

80. Minko, Y.; Pasco, M.; Lercher, L.; Marek, I. Nat. Protoc. 2013, 8, 749-754. doi:10.1038/nprot.2013.036

81. Davies, H. M. L.; Lee, G. H. Org. Lett. 2004, 6, 1233-1236. doi:10.1021/ol049928c

82. Marek, I.; Simaan, S.; Masarwa, A. Angew. Chem., Int. Ed. 2008, 47 1982. doi:10.1002/anie.200890046

83. Dian, L.; Müller, D. S.; Marek, I. Angew. Chem., Int. Ed. 2017, 56, 6783-6787. doi:10.1002/anie.201701094

84. Parra, A.; Amenós, L.; Guisán-Ceinos, M.; López, A.; García Ruano, J. L.; Tortosa, M. J. Am. Chem. Soc. 2014, 136, 15833-15836. doi:10.1021/ja510419z

85. Müller, D. S.; Marek, I. J. Am. Chem. Soc. 2015, 137, 15414-15417. doi:10.1021/jacs.5b11220

86. Panek, E. J.; Kaiser, L. R.; Whitesides, G. M. J. Am. Chem. Soc. 1977, 99, 3708-3713. doi:10.1021/ja00453a032

87. DeBergh, J. R.; Spivey, K. M.; Ready, J. M. J. Am. Chem. Soc. 2008, 130, 7828-7829. doi:10.1021/ja803480b

88. Zhang, D.; Ready, J. M. Org. Lett. 2005, 7, 5681-5683. doi:10.1021/ol052413g

89. Simaan, M.; Marek, I. Angew. Chem., Int. Ed. 2018, 57, 1543-1546. doi:10.1002/anie.201710707

90. Sommer, H.; Marek, I. Chem. Sci. 2018, 9, 6503-6508. doi:10.1039/c8sc02085j

91. Dian, L.; Marek, I. Angew. Chem., Int. Ed. 2018, 57, 3682-3686. doi:10.1002/anie.201713324

92. Müller, D. S.; Werner, V.; Akyol, S.; Schmalz, H.-G.; Marek, I. Org. Lett. 2017, 19, 3970-3973. doi:10.1021/acs.orglett.7b01661

\section{License and Terms}

This is an Open Access article under the terms of the Creative Commons Attribution License (http://creativecommons.org/licenses/by/4.0). Please note that the reuse, redistribution and reproduction in particular requires that the authors and source are credited.

The license is subject to the Beilstein Journal of Organic Chemistry terms and conditions:

(https://www.beilstein-journals.org/bjoc)

The definitive version of this article is the electronic one which can be found at: doi:10.3762/bjoc. 15.71 